\title{
Clinical characteristics and risk factors of mirror syndrome: a retrospective case-control study
}

Zhenyan $\mathrm{Han}^{\dagger}$, Xiaodan Chen ${ }^{\dagger}$, Qingqing Wang, Jin Zhou, Yan Guo, Hongying Hou ${ }^{*}$ and Yuan Zhang*

\begin{abstract}
Background: Mirror syndrome (MS) is a rare obstetric disorder complicated with high maternal morbidity and fetal mortality. MS is often misdiagnosed or underdiagnosed due to the low incidence and lack of awareness of its diverse features. This study aimed to summarise the etiology, clinical characteristics, and risk factors of MS among mothers with fetal hydrops.
\end{abstract}

Methods: This retrospective case-control study included 37 pregnant women with fetal hydrops in the second and third trimesters from 58,428 deliveries performed at the Third Affiliated Hospital of Sun Yat-Sen University between January 2012 and December 2020. Cases were categorized as MS and non-MS according to the presence or absence of maternal mirroring symptoms. Binary logistic regression was performed for analysis.

Results: Fourteen women developed MS with an overall incidence of $0.024 \%(14 / 58,428)$ and $37.8 \%(14 / 37)$ in the fetal hydrops cases. Among the $11 \mathrm{MS}$ cases with known associated etiologies, seven had alpha thalassemia major. Onset of fetal hydrops was later (27.8 vs. 23.0 weeks) and the rate of placental thickening was higher (85.7\% vs. 34.8\%) in the MS group than in the non-MS group $(P<0.05)$. Regarding maternal characteristics, the MS group had higher maternal morbidity ( $85.7 \%$ vs. $8.7 \%)$, more weight gain ( $9.0 \mathrm{vs.} 5.5 \mathrm{~kg}$ ), higher rates of hypertension $(35.7 \mathrm{vs} .0 \%)$ and proteinuria (64.3\% vs. 4.3\%), and lower levels of hemoglobin ( $88 \mathrm{vs.} 105 \mathrm{~g} / \mathrm{L}$ ) and serum albumin ( $25.8 \mathrm{vs} .35 .0 \mathrm{~g} / \mathrm{L})$ than the non-MS group $(P<0.05)$. Logistic regression analysis showed that onset of fetal hydrops at $\geq 24$ weeks and placental thickening were associated with the risk of MS among fetal hydrops cases (OR 15.83, 95\% Cl 1.56-160.10 and OR $8.63,95 \% \mathrm{Cl} 1.29-57.72$, respectively).

Conclusions: MS is relatively common among fetal hydrops cases in the late second and third trimesters, and alpha thalassemia major is the main etiology for fetal hydrops and also MS in this population. Complicated with high maternal morbidity, the key maternal features of MS include more weight gain, hemodilution, and hypertension. Among those with fetal hydrops, the onset time of $\geq 24$ weeks and placental thickening are risk factors for MS.

Keywords: Mirror syndrome, Fetal hydrops, Placental thickening, Hemodilution

*Correspondence: houhongy@mail.sysu.edu.cn; zhangy69@mail.sysu.edu.cn ${ }^{\dagger}$ Zhenyan Han and Xiaodan Chen contributed equally to this work. Department of Obstetrics and Gynecology, Third Affiliated Hospital of Sun Yat-sen University, No. 600 Tianhe Road, Tianhe District, Guangzhou 510630, Guangdong Province, China

\begin{abstract}
Introduction
Mirror syndrome (MS) also known as "triple edema" or Ballantyne syndrome, is a rare disorder affecting pregnant women [1]. It describes the unusual association of fetal hydrops and placental edema with diverse maternal edematous manifestations [1-3]. As most of the published studies in the literature on MS consist of sporadic
\end{abstract}

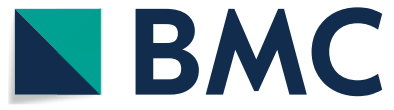

(c) The Author(s) 2021. Open Access This article is licensed under a Creative Commons Attribution 4.0 International License, which permits use, sharing, adaptation, distribution and reproduction in any medium or format, as long as you give appropriate credit to the original author(s) and the source, provide a link to the Creative Commons licence, and indicate if changes were made. The images or other third party material in this article are included in the article's Creative Commons licence, unless indicated otherwise in a credit line to the material. If material is not included in the article's Creative Commons licence and your intended use is not permitted by statutory regulation or exceeds the permitted use, you will need to obtain permission directly from the copyright holder. To view a copy of this licence, visit http://creativecommons.org/licenses/by/4.0/. The Creative Commons Public Domain Dedication waiver (http://creativeco mmons.org/publicdomain/zero/1.0/) applies to the data made available in this article, unless otherwise stated in a credit line to the data. 
case reports that mainly focused on severe presentations, its incidence and pathophysiology are remain unclear [2, 3]. In fact, MS is often underdiagnosed or misdiagnosed due to unnoticed maternal symptoms of an abnormal fetus, or unawareness of MS and sometimes its preeclampsia-like manifestations [4]. Some researchers have hypothesized that MS shares a similar pathogenesis to preeclampsia with the same pattern of increased inflammatory markers or placental factors, which could be used as a diagnostic tool for MS; however, there is insufficient evidence to support this theory [5-8].

It has been reported that maternal morbidity usually increases in MS, and fetal mortality has been reported to be as high as $67.26 \%$ [3]. Most patients require induction of labor or termination of pregnancy because of irreversible fetal hydrops and poor prognosis. However, until now, the characteristics of MS have not been fully elucidated, and the risk factors for MS among hydropic fetuses are still unknown due to paucity of cases. In this study, we retrospectively compared MS cases with nonMS fetal hydrops controls to analyze the clinical characteristics and risk factors of MS.

\section{Methods}

\section{Study design and subjects}

A total of 59 pregnant women with fetal hydrops were retrospectively reviewed from 58, 428 deliveries at the Third Affiliated Hospital of Sun Yat-Sen University between January 2012 and December 2020. Twenty-two patients were excluded since they terminated their pregnancies in the first trimester and had no maternal complications. The remaining 37 patients who were in the second and third trimesters were divided into the MS and the non-MS groups according to the presence or absence of maternal mirroring symptoms. This study was approved by the Institutional Review Board of the Third Affiliated Hospital of Sun Yat-Sen University and written informed consent was obtained from each participant.

\section{Data collection}

Maternal data included age, primiparity, body weight gain $(\mathrm{kg})$, blood pressure $(\mathrm{mmHg})$, hemoglobin $(\mathrm{g} / \mathrm{L})$, hematocrit $(\%)$, platelets $\left(\times 10^{9} / \mathrm{L}\right)$, albumin $(\mathrm{g} / \mathrm{L})$, uric acid $(\mu \mathrm{mol} / \mathrm{L})$, creatinine $(\mu \mathrm{mol} / \mathrm{L})$ and urinary protein. Fetal features included the time of onset of fetal hydrops (gestational weeks), site of edema, structural anomalies, volume of amniotic fluid, and placental thickness. Maternal and fetal outcomes included gestational weeks at time of delivery, mode of delivery, complications, transfusion of blood products, intensive care unit (ICU) admission, length and cost of hospital stay, neonatal death or survival, birth weight, placental weight, and pathologic examination.

\section{Diagnostic criteria}

The diagnostic criteria were as follows: a) Fetal hydrops was defined as the pathological fluid accumulation in $\geq 2$ different fetal compartments, including skin edema (skin thickness $>5 \mathrm{~mm}$ ), ascites, pleural effusion, pericardial effusion, and other sonographic findings such as placental thickening or polyhydramnios (atypical fetal hydrops manifests as simple skin edema or body cavity effusion) [9]; b) placental thickening, indicated by ultrasounddetected placental thickness of $\geq 40$ or $\geq 60 \mathrm{~mm}$ in the second and third trimesters, respectively [9]; c) placental edema confirmed by pathology of the placenta after delivery; and d) for MS, maternal edematous manifestations characterized by accumulation of excessive fluid within subcutaneous and body cavities, weight gain, and preeclampsia-like symptoms, which were associated with fetal hydrops and placental edema.

\section{Statistical analysis}

Data are presented as median (interquartile range) for continuous variables and number (percentage) for categorical variables. Differences in continuous variables were compared between groups using Mann-Whitney U test. Fisher's exact test was performed to analyze the categorical variables. The risk factors for MS were analyzed using binary logistic regression model. Data analysis was performed using SPSS statistical software version 27.0 (IBM; Armonk, NY, USA). A $P$-value of $<0.05$ was considered statistically significant.

\section{Results}

Among the 37 pregnant women with fetal hydrops, 14 (37.8\%) patients who developed MS were enrolled in the MS group and the remaining 23 cases in the nonMS group. The overall incidence of MS in this population was $0.024 \%(14 / 58,428)$. Genetic analysis for fetal hydrops was conducted in 27 cases, and 17 fetuses were diagnosed with alpha thalassemia major. The other known associated etiologies included twin-to-twin transfusion syndrome (TTTS) (3/37), structural cardiac abnormalities (2/37), congenital cystic adenomatoid malformation (1/37), fetal anemia (1/37), and placental chorioangioma (1/37). All 23 patients in the non-MS group and 12 patients in the MS group opted to terminate their pregnancies.

\section{Clinical features and outcomes of MS}

Among the14 cases, the time of diagnosis of MS ranged from 22.6 to 34 gestational weeks. The etiology was identified in 11 cases and included alpha thalassemia major (7/14), structural cardiac abnormalities (2/14), TTTS $(1 / 14)$, and fetal anemia (1/14). Prenatal sonographic 
findings indicated fetal hydrops (14/14), placental thickening (12/14), polyhydramnios (6/14), and oligohydramnios (3/14). Maternal clinical manifestations included edema (14/14: lower limb edema [10/14], ascites [6/14], pleural effusion, [5/14]), anemia (14/14), hypoalbuminemia (12/14), proteinuria (7/14) and hypertension (5/14). After delivery, placental edema was confirmed in all 14 cases by both gross and histologic placental examinations (Table S1).

Of the 12 pregnant women who opted for termination, seven patients had uneventful vaginal deliveries, and five underwent a cesarean section for various indications, which included maternal complications and failed labor induction. The other two patients for expectant management eventually underwent emergency cesarean section due to critical maternal conditions; two very preterm twin infants survived and one preterm neonate died. Maternal complications occurred in 12 cases, including postpartum hemorrhage (7/14), placenta accreta (5/14), acute left heart failure (3/14), renal dysfunction (3/14), pulmonary edema (2/14), HELLP (hemolysis, elevated liver enzymes, low platelet count) syndrome (2/14), liver dysfunction (1/14), placental abruption (1/14), and disseminated intravascular coagulation (DIC) (1/14). The ICU admission rate was $42.9 \%(6 / 14)$, and the median time for maternal symptoms to resolve was 7.5 days (range: 2-10 days) after delivery.

\section{Differences between MS and non-MS groups}

Compared to the non-MS group, the median gestational age at fetal hydrops onset was significantly later (27.8 vs. 23.0 weeks, $P=0.003$ ) and the proportion of placental thickening was higher $(85.7 \%$ vs. $34.8 \%, P=0.006)$ in the MS group. Regarding maternal symptoms, pregnant women in the MS group had more weight gain (9.0 vs. $5.5 \mathrm{~kg}, P=0.003)$ and higher rates of hypertension $(35.7 \%$ vs. $0 \%, P=0.005)$, anemia $(100 \%$ vs. $65.2 \%, P=0.015)$, and proteinuria $(64.3 \%$ vs. $4.3 \%, P<0.001)$. Moreover, their hemoglobin levels ( 88 vs. $105 \mathrm{~g} / \mathrm{L}, P<0.001)$, platelet counts $\left(155\right.$ vs. $\left.237 \times 10^{9} / \mathrm{L}, P=0.005\right)$, and serum albumin levels $(25.8$ vs. $35.0 \mathrm{~g} / \mathrm{L}, P<0.001)$ were significantly lower. In contrast, the levels of uric acid (546 vs. $290 \mu \mathrm{mol} / \mathrm{L}, P=0.042$ ) and creatinine (59 vs. $44 \mu \mathrm{mol} / \mathrm{L}$, $P=0.002)$ were higher in the MS group. As for outcomes, the rates of cesarean section, postpartum hemorrhage, blood product transfusion, and ICU admission were significantly higher in the MS group than in the non-MS group (50\% vs. $0 \%, P<0.001 ; 50 \%$ vs. $4.3 \%, P=0.002$; $64.3 \%$ vs. $4.3 \%, P<0.001$; and $42.9 \%$ vs. $0 \%, P=0.001$; respectively). Meanwhile, the median length of hospital stay was longer and the costs were significantly higher in the MS group (Table 1).

\section{Risk factors for MS}

MS is characterized as "triple edema", and fetal and/or placental edema are precursors of maternal edematic manifestations. Therefore, the fetal and placental parameters associated with the edematous manifestations were chosen as risk factors of MS among cases with fetal hydrops. Binary logistic regression analysis showed that at time of fetal hydrops onset $\geq 24$ weeks (odd ration [OR] 15.83, 95\% confidence interval [CI] 1.56-160.10) and placental thickening (OR 8.63, 95\% CI 1.29-57.72) were risk factors related to the MS (Table 2).

\section{Discussion}

Although MS is a rare obstetric disease, the present case-control study found that it was relatively prevalent among fetal hydrops cases with an incidence of $37.8 \%$ $(14 / 37)$ in the late second and third trimesters. The most common etiology of hydropic fetuses in southern China was alpha thalassemia major, and the fetal prognosis was very poor in both MS and non-MS groups. However, in the MS group, maternal morbidity increased with higher rates of postpartum hemorrhage, blood products transfusions, and ICU admissions; the key maternal features of MS included more weight gain, hemodilution and hypertension. In addition, our findings indicated that the time of onset of fetal hydrops at $\geq 24$ weeks and prenatal placental thickening were risk factors for MS.

Since maternal edema is related to fetal hydrops and placental edema, any of the conditions associated with fetal hydrops or placental edema may cause MS. In southern China, alpha thalassemia major, which accounts for $28.4-55.1 \%$ of non-immune hydrops fetalis [10, 11], is also the common cause of MS. In our study, nearly half $(17 / 37,45.9 \%)$ of hydropic fetuses in the second and third trimesters were caused by alpha thalassemia major, and seven cases $(7 / 17,41.2 \%)$ developed MS. The high proportion of alpha thalassemia major in our study was inconsistent with frequently reported $\mathrm{Rh}$-isoimmunization and viral infections in Western countries, which could be explained by differences in regions and populations. The other known etiologies included TTTS, fetal congenital structural anomalies, and placental chorioangioma, which were also common in previous studies [2, 3].

Although the maternal features of MS varied widely, all patients in the MS group manifested consistent symptoms of edema and hemodilution, characterized by lower extremity pitting edema, ascites, pleural effusion, anemia and hypoalbuminemia. Four patients presented with hypertension and proteinuria, and two of them developed HELLP syndrome before giving birth. Some studies have found that the changes in multiple 
Table 1 Comparison of clinical data between mirror syndrome group and non-mirror syndrome group

\begin{tabular}{|c|c|c|c|}
\hline Clinical Profiles & Non-mirror group $(n=23)$ & Mirror group $(n=14)$ & $P$ value \\
\hline \multicolumn{4}{|l|}{ Fetal features } \\
\hline Time of fetal hydrops onset (wks) & $23.0(9.4)$ & $27.8(4.7)$ & 0.003 \\
\hline Placental thickening & $8 / 23(34.8 \%)$ & $12 / 14(85.7 \%)$ & 0.006 \\
\hline Polyhydramnios & $4 / 23(17.4 \%)$ & $6 / 14(42.9 \%)$ & 0.132 \\
\hline \multicolumn{4}{|l|}{ Maternal features } \\
\hline Maternal age (years) & $28.0(5.0)$ & $28.5(9.0)$ & 0.699 \\
\hline Primipara & $11 / 23(47.8 \%)$ & $4 / 14(28.6 \%)$ & 0.314 \\
\hline Body weight gain & $5.5(6.0)$ & $9.0(8.0)$ & 0.003 \\
\hline Hypertension & $0 / 23(0)$ & $5 / 14(35.7 \%)$ & 0.005 \\
\hline Systolic Blood Pressure (mmHg) & $115(12)$ & $131(24)$ & $<0.001$ \\
\hline Diastolic Blood Pressure (mmHg) & $64(15)$ & $82(13)$ & $<0.001$ \\
\hline Anemia & 15/23 (65.2\%) & $14 / 14(100 \%)$ & 0.015 \\
\hline Hemoglobin (g/L) & $105(31)$ & $88(31)$ & $<0.001$ \\
\hline Hematocrit (\%) & $31.8(3.6)$ & $26.4(7.1)$ & $<0.001$ \\
\hline Platelet counts $\left(\times 10^{9} / \mathrm{L}\right)$ & $237(91)$ & $155(122)$ & 0.005 \\
\hline Serum albumin (g/L) & $35.0(3.2)$ & $25.8(4.1)$ & $<0.001$ \\
\hline Uric Acid ( $\mu \mathrm{mol} / \mathrm{L})$ & $290(32)$ & $546(324)$ & 0.042 \\
\hline Creatinine $(\mu \mathrm{mol} / \mathrm{L})$ & $44(8)$ & $59(44)$ & 0.002 \\
\hline Proteinuria & $1 / 23(4.3 \%)$ & $9 / 14(64.3 \%)$ & $<0.001$ \\
\hline \multicolumn{4}{|l|}{ Outcomes } \\
\hline Termination of pregnancy & $23 / 23(100 \%)$ & $12 / 14(85.7 \%)$ & - \\
\hline Gestational age at delivery (wks) & $25.4(8.9)$ & $29.1(5.9)$ & 0.034 \\
\hline Cesarean section & $0 / 23(0)$ & $7 / 14(50 \%)$ & $<0.001$ \\
\hline Placental edema & 15/23 (65.2\%) & 14/14 (100\%) & 0.015 \\
\hline Maternal morbidity & $2 / 23(8.7 \%)$ & $12 / 14(85.7 \%)$ & $<0.001$ \\
\hline Postpartum hemorrhage & $1 / 23(4.3 \%)$ & $7 / 14(50 \%)$ & 0.002 \\
\hline Placenta accreta & $2 / 23(8.7 \%)$ & $5 / 14(35.7 \%)$ & 0.08 \\
\hline Other complications & $0 / 23(0)$ & $10 / 14(71.4 \%)$ & $<0.001$ \\
\hline Blood products transfusion & $1 / 23(4.3 \%)$ & 9/14 (64.3\%) & $<0.001$ \\
\hline Intensive care unit admission & $0 / 23(0)$ & $6 / 14(42.9 \%)$ & 0.001 \\
\hline Length of hospital stay (days) & $5(3)$ & $11(5)$ & $<0.001$ \\
\hline Cost (dollars) & $582(483)$ & $3597(4023)$ & $<0.001$ \\
\hline
\end{tabular}

Values are median (interquartile range) or number (percentage)

Table 2 Logistic regression analysis of risk factors for mirror syndrome

\begin{tabular}{lll}
\hline Variables & OR $\mathbf{( 9 5 \% ~ C l )}$ & $P$ value \\
\hline $\begin{array}{l}\text { Time of fetal hydrops onset } \\
\geq 24 \text { weeks }\end{array}$ & $15.83(1.56-160.10)$ & 0.019 \\
Placental thickening & $8.63(1.29-57.72)$ & 0.026 \\
\hline
\end{tabular}

Abbreviation: OR Odds ratio, $\mathrm{Cl}$ Confidence interval

placental factors associated with MS have the same pattern as preeclampsia [5-8]. This overlap between MS and preeclampsia can easily lead to misdiagnosis. However, consistent with previously reported cases of MS with maternal hemodilution [2, 3, 12, 13], our laboratory findings showed that the levels of hemoglobin, hematocrit, platelets and serum albumin were significantly lower in the MS group than in the nonMS group. Regardless of the fetal and placental causes, the hemodilution observed in cases of MS compared with typical hemoconcentration of preeclampsia may be considered in the differential diagnosis of these two diseases.

The prognosis of hydropic fetuses is generally poor and depends on the etiology and antenatal therapy $[2,3$, 13]. In our study, the causes of hydrops were identified prenatally in $67.6 \%(25 / 37)$ of patients, and the most common etiology was alpha thalassemia major (17/37). All the parents in the non-MS group and $85.7 \%(12 / 14)$ 
in the MS group opted to terminate their pregnancies due to unsatisfactory guarantee for good fetal prognosis or worsening maternal conditions. Similar to previous reports [2,3], no maternal mortality occurred in the MS group. However, maternal morbidity was as high as $85.7 \%$, which was significantly higher than $8.7 \%$ in the non-MS group. Postpartum hemorrhage occurred in half of the patients in the MS group and the potential causes included placenta accreta, placentomegaly and maternal hemodilution, which are also features of MS. Moreover, nearly two-thirds of the patients in our study needed blood product transfusions and nearly half underwent ICU admission due to acute maternal heart failure, pulmonary edema, or DIC. However, the median time for resolution of maternal manifestations was 7.5 days (range: $2-10$ days) after delivery, which was similar to the 5.5 and 8.9 days reported in other literatures $[2,3]$. These adverse maternal outcomes and the subsequent resolution following delivery highlight the importance of early diagnosis and timely treatment of MS.

In this study, 37.8\% (14/37) of fetal hydrops cases progressed to MS, implying that MS was relatively common among fetal hydrops cases, even though the actual incidence of MS at our hospital was as low as $0.024 \%$. Thus, investigating the potential risk factors of MS is important for the early detection and close surveillance of high-risk pregnant women. However, to the best of our knowledge, there are no published studies on the risk factors for MS due to a paucity of cases or lack of awareness of this problem. MS mainly occurs during the late second and third trimesters $[2,3]$. Among our MS cases, the median gestational age of fetal hydrops onset was 27.8 weeks, which was close to a previous report of 26.4 weeks [3] and significantly later than the median of 23 weeks in the non-MS group. Multivariate analysis showed that the time of fetal hydrops onset at $\geq 24$ gestational weeks was an independent risk factor for MS; therefore, more attention should be paid to this high-risk population. Although the pathogenesis of MS is still unclear, some studies have suggested that placental abnormalities may be the inciting etiology $[14,15]$. Our results showed that placental thickening was also a risk factor for MS. This finding highlights the importance of evaluating the placenta in hydropic fetalis cases.

Some limitations of our study should be discussed. First, despite MS being a rare obstetric condition, this retrospective study from a single center with a small sample may lead to selection bias. Second, nearly all patients in this study opted to terminate their pregnancies following diagnosis of fetal hydrops, and the actual rate of fetal survival and the efficacy of intrauterine interventions could not be assessed. Lastly, clinical data did not consider any pathophysiologic markers, and the mechanism of MS could not be discussed herein.

\section{Conclusion}

MS is a common obstetric disease among fetal hydrops cases in late second and third trimesters. The main cause of fetal hydrops and also MS is alpha thalassemia major in southern China. With diverse maternal manifestations, the key features include more weight gain, hemodilution, and hypertension. The high maternal morbidity is mainly attributed to postpartum hemorrhage. In addition, this study demonstrated that the time of onset of fetal hydrops at $\geq 24$ weeks and prenatal placental thickening are both risk factors for MS; thus, more attention should be paid to high-risk populations that have these characteristics. Additional prospective studies with larger study populations of fetal hydrops and MS cases are needed to further assess these risk factors.

\section{Abbreviations}

MS: Mirror syndrome; ICU: Intensive care unit; TTTS: Twin-to-twin transfusion syndrome; HELLP: Hemolysis, elevated liver enzymes, low platelet count syndrome; DIC: Disseminated intravascular coagulation; SD: Standard deviations; OR: Odd ration; Cl: Confidence interval.

\section{Supplementary Information}

The online version contains supplementary material available at https://doi. org/10.1186/s12884-021-04143-3.

Additional file 1.

\section{Acknowledgments}

We would like to thank all the doctors and nurses who facilitated this study at the Third Affiliated Hospital of Sun Yat-Sen University. We also would like to thank Editage (www.editage.com) for the English language editing.

\section{Authors' contributions}

All authors have contributed to this paper. HYH, YZ and ZYH proposed the conception and designed the study. QQW, JZ and YG performed the study and collected data. ZYH and XDC performed statistical analysis and wrote the manuscript, and $Y Z$ revised it critically. All authors read and approved the final manuscript.

\section{Funding}

Not applicable.

\section{Availability of data and materials}

The datasets used and/or analysed during the current study are available from the corresponding authors on reasonable request.

\section{Declarations}

Ethics approval and consent to participate

This study was approved by the Institutional Review Boards of the Third Affiliated Hospital of Sun Yat-sen University and written informed consent was obtained from each participant women. All methods were performed in accordance with the relevant guidelines and regulations. 


\section{Competing interests}

The authors declare that they have no competing interests.

Received: 5 April 2021 Accepted: 13 September 2021

Published online: 28 September 2021

\section{References}

1. Kaiser $\mathrm{H}$. Ballantyne and triple edema. Am J Obstet Gynecol. 1971:110:115-20.

2. Braun T, Brauer M, Fuchs I, Czernik C, Dudenhausen JW, Henrich W, et al. Mirror syndrome: a systematic review of fetal associated conditions, maternal presentation and perinatal outcome. Fetal Diagn Ther. 2010:27:191-203.

3. Allarakia S, Khayat HA, Karami MM, Aldakhil AM, Kashi AM, Algain AH, et al. Characteristics and management of mirror syndrome: a systematic review (1956-2016). J Perinat Med. 2017;45:1013-21.

4. Teles Abrao Trad A, Czeresnia R, Elrefaei A, Ibirogba ER, Narang K, Ruano $R$. What do we know about the diagnosis and management of mirror syndrome? J Matern Fetal Neonatal Med. 2021;1-6. https://doi.org/10. 1080/14767058.2020.1844656. Epub ahead of print.

5. Espinoza J, Romero R, Nien JK, Kusanovic JP, Richani K, Gomez R, et al. A role of the anti-angiogenic factor sVEGFR-1 in the 'mirror syndrome' (Ballantyne's syndrome). J Matern Fetal Neonatal Med. 2006;19:607-13.

6. De Oliveira L, Sass N, Boute T, Moron AF. sFlt-1 and PIGF levels in a patient with mirror syndrome related to cytomegalovirus infection. Eur J Obstet Gynecol Reprod Biol. 2011;158:366-7.

7. Llurba E, Marsal G, Sanchez O, Dominguez C, Alijotas-Reig J, Carreras E, et al. Angiogenic and antiangiogenic factors before and after resolution of maternal mirror syndrome. Ultrasound Obstet Gynecol. 2012;40:367-9.
8. Hobson SR, Wallace EM, Chan YF, Edwards AG, Teoh MWT, Khaw AP-L. Mirroring preeclampsia: the molecular basis of Ballantyne syndrome. J Matern Fetal Neonatal Med. 2020;33:768-73.

9. Society for Maternal-Fetal M, Norton ME, Chauhan SP, Dashe JS. Society for maternal-fetal medicine (SMFM) clinical guideline \#7: nonimmune hydrops fetalis. Am J Obstet Gynecol. 2015;212:127-39.

10. Liao C, Wei J, Li Q, Li J, Li L, Li D. Nonimmune Hydrops Fetalis diagnosed during the second half of pregnancy in southern China. Fetal Diagn Ther. 2007:22:302-5.

11. Meng D, Li Q, Hu X, Wang L, Tan S, Su J, et al. Etiology and outcome of non-immune Hydrops Fetalis in southern China: report of 1004 cases. Sci Rep. 2019;9:10726.

12. Hirata G, Aoki S, Sakamaki K, Takahashi T, Hirahara F, Ishikawa H. Clinical characteristics of mirror syndrome: a comparison of 10 cases of mirror syndrome with non-mirror syndrome fetal hydrops cases. J Matern Fetal Neonatal Med. 2016;29:2630-4.

13. Chen R, Liu M, Yan J, Chen F, Han Q, Zheng L, et al. Clinical characteristics of mirror syndrome: a retrospective study of 16 cases. J Obstet Gynaecol. 2020;41:73-6.

14. Bixel K, Silasi M, Zelop CM, Lim KH, Zsengeller Z, Stillman IE, et al. Placental origins of angiogenic dysfunction in mirror syndrome. Hypertens Pregnancy. 2012;31:211-7.

15. Graham N, Garrod A, Bullen P, Heazell AE. Placental expression of anti-angiogenic proteins in mirror syndrome: a case report. Placenta. 2012;33:528-31.

\section{Publisher's Note}

Springer Nature remains neutral with regard to jurisdictional claims in published maps and institutional affiliations.
Ready to submit your research? Choose BMC and benefit from:

- fast, convenient online submission

- thorough peer review by experienced researchers in your field

- rapid publication on acceptance

- support for research data, including large and complex data types

- gold Open Access which fosters wider collaboration and increased citations

- maximum visibility for your research: over $100 \mathrm{M}$ website views per year

At BMC, research is always in progress.

Learn more biomedcentral.com/submissions 